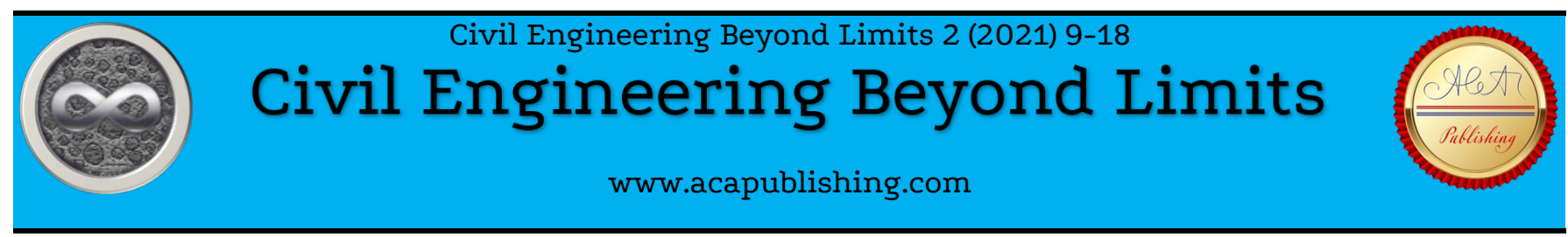

Research Article

\title{
Deformations of a plastic tube with concrete-infill under direct load
}

\author{
Nwzad Abduljabar Abdulla \\ Department of Civil Engineering, Salahaddin University, Kirkuk Rd., Erbil, Iraq
}

\section{Keywords}

Plastic tube;

Axial strain;

Normalized confinement stiffness;

Database;

Strain model.

\begin{abstract}
Confinement of concrete columns can be an effective means of enhancing structural members' deformation-alternative materials such as UPVC tube show elastic-plastic behavior with considerable elongations at failure. The material ductility features significant deformations that usually considered to be belonging to the set of mechanical properties. The tube can be applied for encasing concrete, thereby influencing the deformability capacity of a column. The current work aims to evaluate the axial strain of plastic tubes with concrete-infill (PTCI) specimens tested under uniaxial compression load. A strain model was developed for PTCI specimens using a normalized confinement stiffness procedure, based on a database of experimental results from recent studies 2019-2020 and those of the present study. Five existing FRP-confined concrete models and the developed model were employed to predict PTCI columns' strain, and the predictions were compared with experimental results in the database. Three statistical indexes were used to evaluate the proposed and the three existing FRP-confined concrete strain models' performance. The indexes included: Average absolute relative error (AAE), Normalized root-mean-square error (NRMSE), and coefficient of correlation (R2). The comparison shows the proposed model to give more close prediction to the experimental test data and the comprehensive database to yield the lowest average absolute error (AAE). The root means square error (RMSE) compared with other models in the present study.
\end{abstract}

\section{Introduction}

Engineering plastics such as unplasticized polyvinyl chloride (uPVC) have been used in civil engineering and construction applications for several decades. However, there is a need to promote these new materials in civil engineering applications to protect and contain concrete elements. Based on its technological and economic advantages, the performance of these tubular elements under harsh environmental conditions has been established previously. Several studies recently explored the potential use of plastic tubes for structural concrete encasement, representing new trends in searching for alternative materials.

Composites like a concrete-filled steel tube (CFST) have shortcomings such as high cost and corrosion. PTCI was reported as a viable alternative for conventional steel tube for structural applications provided that appropriate design methodologies are employed. As a non-metallic pour-in form for concrete [1], the plastic tube can improve column constructability and enhance its resistance to environmental influences (chemical plants, large water tanks, and underground car parks). PTCI columns with an aspect ratio of two $(\mathrm{h} / \mathrm{D}=2)$ were tested under compression load [2]. The post-peak stressstrain behavior of PTCI specimens proved to be affected by the total thickness/diameter ratio (2t/D). The absolute value of the slope decreased as the $2 t / D$ proportion increased.

The aggregate characteristics were reported to be influential parameters that affected short PTCI columns' performance under applied load [3]. In experimental work, two series of slender PTCI specimens were tested to assess the contribution of plastic tube (PT) in improving the ductility of concrete in PTCI specimens subjected to axial load [4]. The plastic tube was used in three low-cost composite systems for concrete construction [5]. The steel-reinforced hybrid systems demonstrated different rigidities that can ameliorate the deformation capacities and, in a similar manner, to a lesser extent the radial performance of the slender PTCI specimens. The increase in tube thickness was reported to affect steel-reinforced PTCI specimens' ductility when subjected to axial load [6]. To account for the individual load contribution of PTCI components under a compression load, concrete core, and outer PT jacket, a small gap of $1.2 \mathrm{~mm}$ was introduced between the two [7]. The results showed the formation of two peak strains with a compression strain-softening in the falling ranch. To predicate the plastic capacity of PTCI columns with two different mechanisms, composite mode and confining mode, two series of short PTCI specimens were tested, and material failure dominated the test results [8].

Double skin PTCI specimens under axial compression loads were investigated [9], showing considerable ductility enhancement. Drum type failure was the prevalent failure mode, with the internal tubes displaying local buckling. One of the plastic tube's primary deficiencies in the low modulus of elasticity can be overcome using fiber-reinforced polymers (FRP). From the above review, there is no strain model for PTCI, which includes the tube stiffness as one of the main input parameters. The present study's main objective is to adopt a normalized confinement stiffness procedure, which has been previously proposed for FRP [10], to predict a plastic tube's strain capacity with concrete-infill tested under uniaxial load. To achieve this goal, a database of test results of recently published papers 2019- 
2020 was compiled and combined with the current study's experimental results and used to develop a strain model for PTCI specimens tested under compression load.

\section{Experimental program}

\subsection{Materials}

\subsubsection{Coarse aggregate}

Graded crushed river aggregate from the Eski-kalak region north of the country was used as a coarse aggregate for making concrete. Natural river sand of a maximum aggregate size of $4.75 \mathrm{~mm}$ with a fineness modulus of 2.78 was used as the fine aggregate. Both the fine and coarse aggregates were free from impurities. Two mixtures with target strength of 35 and $50 \mathrm{MPa}$ were investigated, and the ingredients were batched by weight, Table 1. To control the slump and have the desired workability, a superplasticizer (SP) was used as a water reducer admixture for the mix with the target strength of $50 \mathrm{MPa}$.

\subsubsection{Plastic molds}

Unplasticized polyvinyl chloride tubes with an external diameter of $110 \mathrm{~mm}$ were cut into two groups, each with three different heights resulting in h/D ratios of 1 to 2 in an increment of 0.5 . Group one had an average tube thickness of $4 \mathrm{~mm}$, whereas group two had an average tube thickness of $6 \mathrm{~mm}$.

Table 1 Properties of concrete mixes

\begin{tabular}{|c|c|c|c|}
\hline Material properties & & Batch 1 & Batch 2 \\
\hline Water & $(\mathrm{Kg})$ & 170 & 150 \\
\hline Cement & $(\mathrm{Kg})$ & 355 & 400 \\
\hline Sand & $(\mathrm{Kg})$ & 680 & 700 \\
\hline Coarse aggregate & $(\mathrm{Kg})$ & 1350 & 1290 \\
\hline $\mathrm{w} / \mathrm{c}$ ratio & & 0.51 & 0.41 \\
\hline Maximum aggregate size & $(\mathrm{mm})$ & 10 & 10 \\
\hline Slump & $(\mathrm{mm})$ & $100 \pm 20$ & $100 \pm 20$ \\
\hline $\begin{array}{l}\text { The specific gravity } \\
\text { of sand }\end{array}$ & & 2.7 & 2.7 \\
\hline $\begin{array}{c}\text { The specific gravity of } \\
\text { aggregate }\end{array}$ & & 2.72 & 2.72 \\
\hline $\begin{array}{c}\text { The specific gravity of } \\
\text { cement }\end{array}$ & & 3.15 & 3.15 \\
\hline Unit weight of concrete & $\mathrm{Kg} / \mathrm{m}^{3}$ & 2370 & 2400 \\
\hline Super-plasticizer & $\%$ & - & 1 \\
\hline Target compressive strength & $(\mathrm{MPa})$ & 30 & 50 \\
\hline
\end{tabular}

\subsection{Mixing}

All the ingredients were mixed in a rotary drum mixer with a capacity of $0.07 \mathrm{~m}^{3}$ under indoor laboratory conditions. All the raw materials were loaded into the mixer and dry mixed for four minutes. Afterward, the water was added, and the mixing continued for another 3-4 minutes until a homogeneous mix was obtained. A standard slump cone was used to measure the workability of fresh concrete. Following the mixing, a part of the new concrete was used for the slump test. The concrete slump was computed as the drop in the height of the cone-shaped concrete. The plastic concrete was cast into the pre-prepared molds for confined and unconfined concrete specimens in two layers, and each layer was compacted for at least 30seconds. After casting, the specimens were covered with wet burlaps and polyethylene sheets for 28days. After that, the control specimens were de-molded by cutting the plastic tube longitudinally using an electric saw. All the details of mixes and specimen designations are summarized in Table 2. Specimens with series S1, S2, and S3 had infill concrete with compressive strength of $35 \mathrm{MPa}$ whereas series S2, S4, and S6 had strength of 50MPa.

\section{Tests}

Uniaxial compression tests were carried out using a $2000 \mathrm{KN}$ universal testing machine. Two linear displacement transducers were used for the vertical displacement control case. The experimental tests were monitored at a speed of $0.2 \mathrm{~mm} / \mathrm{s}$, and beyond the peak load, loading continued until a force of $50 \mathrm{kN}$ was reached to obtain the full stress-strain curves for PTCI specimens. The coupon test of the UPVC sample in tension was shown in Fig. (1), whereas the uPVC tubes' compression test was depicted in Fig. (2). PTCI stub columns, with h/D ratio equal to 0.75 , tested under axial compression load displayed in Fig. (3). The specimen underwent gradual deformations, and Figs. 4(a) and (b) shows the deformation of columns at $50 \%, 70 \%$ of ultimate strain $\varepsilon_{\mathrm{cu}}$. Fig.4(c) illustrates the column's excessive deterioration at $90 \%$ of ultimate strain before final failure.

\section{Discussions}

\subsection{Stress-strain curve}

\subsubsection{Coupons}

The coupons showed considerable flexibility with ductile failure in the post-peak plastic stage, reaching an elongation of more than $44 \%$ at ultimate failure. The stress-strain relationship of the PVC coupons is depicted in Fig. (5), which show four clear zones; elastic, post-yield; peak strain, and post-peak zone. The polymeric tubes offer no exact yield point, and the $0.2 \%$ strain method was used to determine the yield point of coupons and plastic tubes, Fig.(6).

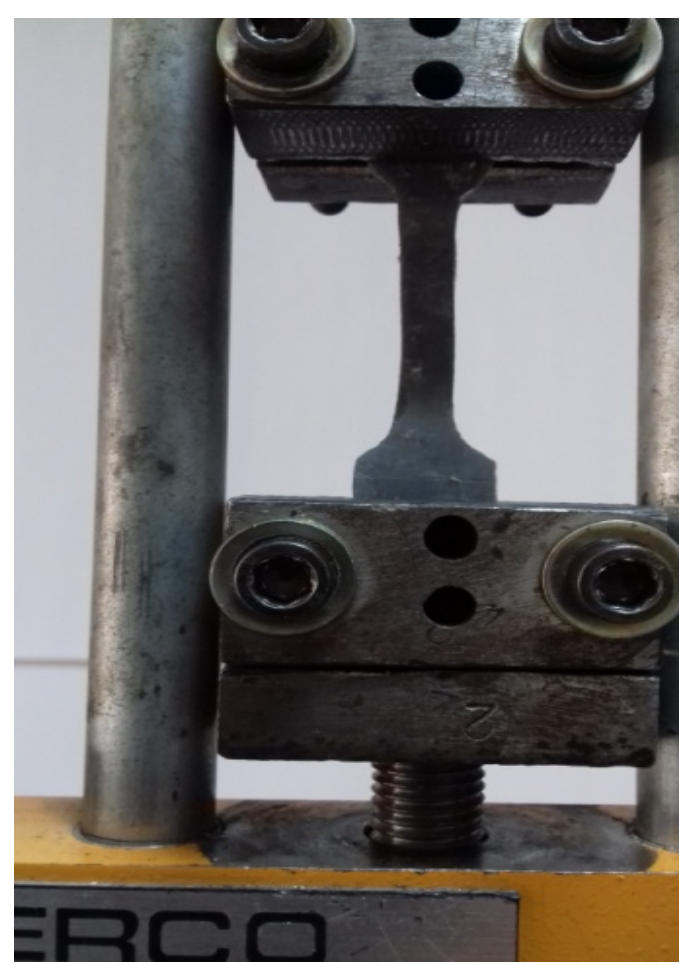

Fig. (1) Coupon test of uPVC samples 


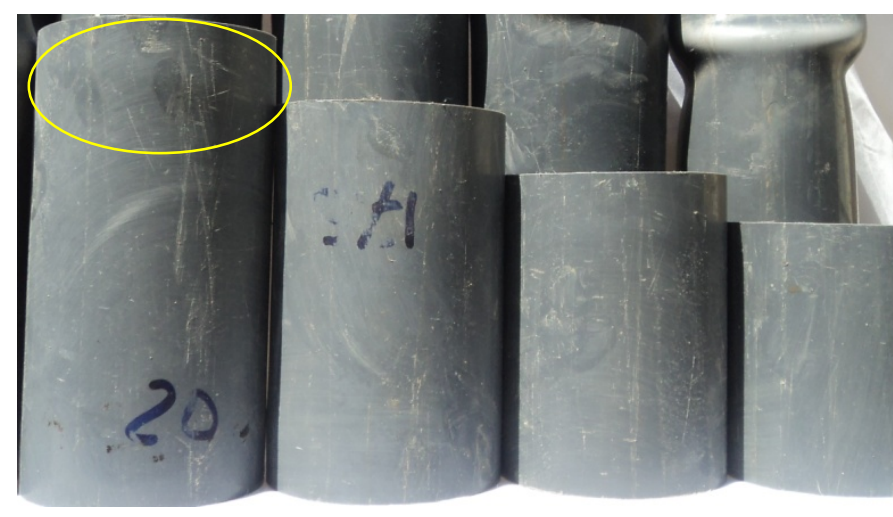

Fig. (2) Failure of uPVC tubes due to local buckling.

\subsubsection{CFPT specimens}

The stress-strain relationship for the first series of PTCI specimens is demonstrated in Fig. (7). The behavior for the unconfined and confined specimens was similar in the elastic stage. The confined specimens started to deform locally at the ends and the mid-height. At these locations, the tube's color began to change from gray to a gray whitish color, which was a sign of permanent deformation in the tube's microstructure. With additional loading, the PTCI peaked at a corresponding strain much more significant than that for unconfined specimens. Beyond the peak load, PTCI stubs' resistance to the applied load started to deteriorate faster for specimens with high-strength concrete infill (S2-H4-1) than specimens with normal strength infill (S1-H4-1).

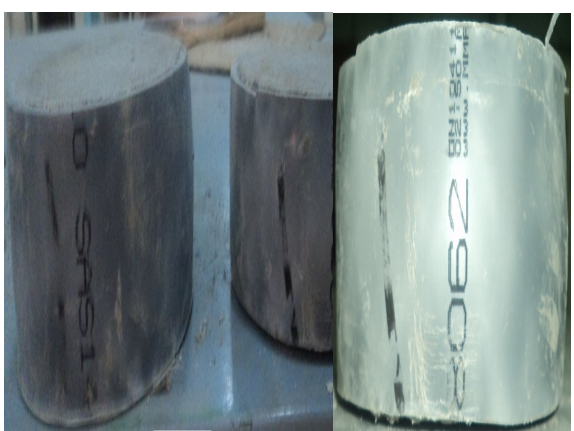

(a)

(b)

Fig. 3 PTCI stubs: (a) (S3-H2-1); (b) (S3-H2-1)

(a)

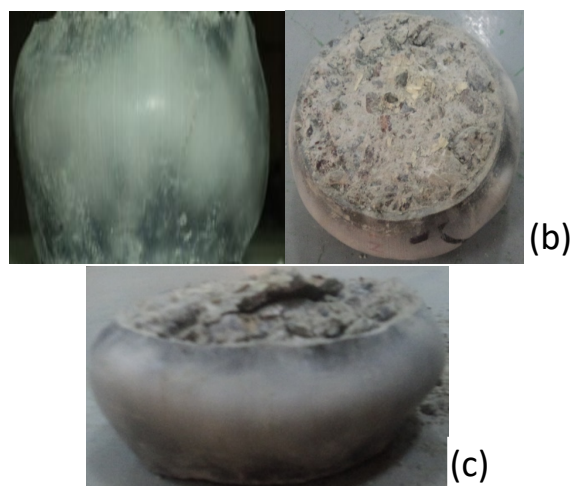

Fig. (4) Failure of PTCI stub columns (S3-H2-2) under axial compression load at (a) $50 \%$ of $\varepsilon_{\mathrm{cu}}$; (b) $70 \%$ of $\varepsilon_{\mathrm{cu}}$; (c) $90 \%$ of $\varepsilon_{\mathrm{cu}}$.

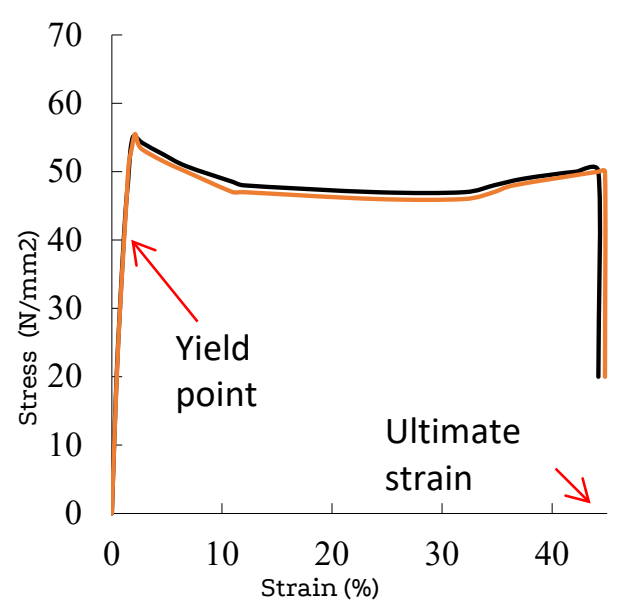

Fig. 5 stress-strain relationship for the coupons tested in axial tension.

Both specimens underwent strain softening and continued to deform, and the ultimate strain (failure strain) reached values greater than 0.16 , which was nearly 40 times greater than the strain at peak stress 0.004 for column S1-H4-1.

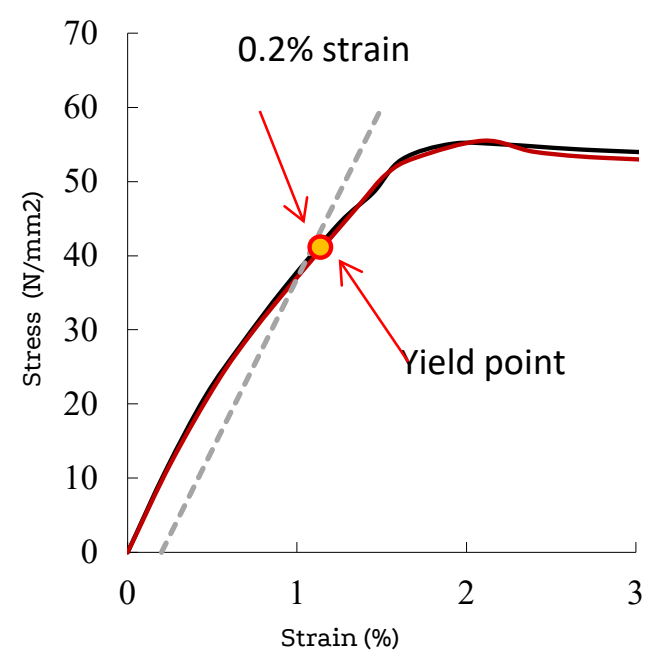

Fig.6 0.2\% strain used to determine the yield point of coupons.

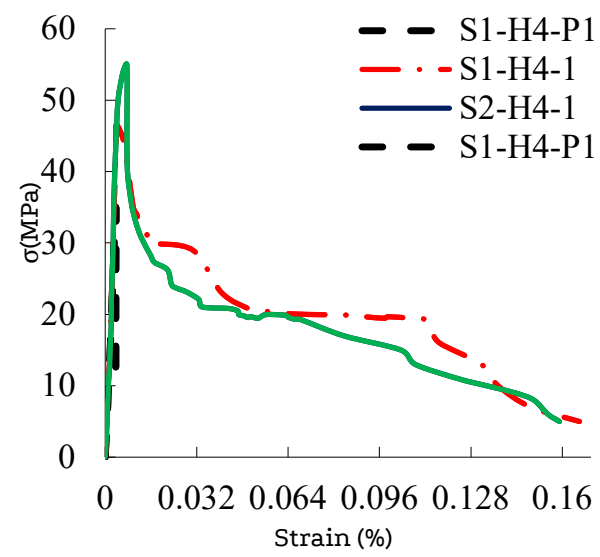

Fig.7 Typical axial stress-strain relationship used for the tested columns 
Such deformations beyond peak load are essential when considering the design of compression members in critical seismic zones where reinforced columns' failure is brittle.

\subsection{Strain models}

Three existing strain models for concrete were confined with the fiber-reinforced polymer used to predict PTCI specimens' strain. It includes the following models:

\subsubsection{Ilki et al. [11]}

$$
\frac{\varepsilon_{c u}}{\varepsilon_{c o}}=1+20\left(\frac{f_{l u}}{f_{c o}}\right)^{0.5}
$$

5.1.2. Wu et al. [12]

$$
\frac{\varepsilon_{c u}}{\varepsilon_{c o}}=1+9.5\left(\frac{f_{l u}}{f_{c o}}\right)
$$

5.1.3 Mohamed H, Masmoudi [13]

$$
\frac{\varepsilon_{c u}}{\varepsilon_{c o}}=2+7.6\left(\frac{f_{l u}}{f_{c o}}\right)
$$

\subsection{Model development}

Many existing stress and strain models for concrete confined with FRP are based on the model for steel-confined concrete developed by Richart et al. [14]:

$$
\begin{aligned}
& \frac{f_{c c}}{f_{c o}}=1+4.1\left(\frac{f l}{f^{\prime} c o}\right) \\
& \frac{\varepsilon_{c c}}{\varepsilon_{c o}}=1+5\left(\frac{f_{c c}^{\prime c c}}{f^{\prime} c o}-1\right)
\end{aligned}
$$

where $\varepsilon_{c c}=$ confined concrete strain, $\varepsilon_{c o}=$ unconfined concrete strain, $f_{c c}=$ confined concrete strength, $f_{c o}^{\prime}=$ unconfined concrete strength, respectively. A large difference in failure strain of FRPconfined concrete has been reported, and values varied from 58 to $61 \%$ of the coupon test strains, mostly based on carbon FRP confinement results $[10,15]$. This behavior was ascribed to the FRP confinement device's multiaxial state of stress and possible stress concentrations throughout the concrete column's surface. For FRPconfined concrete, the confining pressure is given by:

$$
f_{l}=\frac{2 \mathrm{E}_{f} t_{f} \varepsilon_{f e}}{D}
$$

Where $\mathrm{E}_{f}=$ modulus of elasticity; $t_{f}=$ total thickness; $\varepsilon_{f e}=$ effective rupture strain; and $\mathrm{D}=$ concrete specimen diameter.

The effective strain value of FRP confinement is given by:

$$
\varepsilon_{f e}=\kappa_{\varepsilon} \varepsilon_{f u}
$$

where $\kappa_{\varepsilon}=$ strain efficiency factor (a value of 0.55 is recommended for circular cross-sections) and $\varepsilon_{\mathrm{fu}}=$ ultimate tensile strain value of the FRP confinement material measured in coupon tests [10].

ACI 440.2R [16] recommends the confinement ratio (fl/fco) to be larger than 0.08 to avoid a post-peak descending branch based on the work of Lam and Teng $[17,18]$.

$$
\varepsilon_{c c}=\varepsilon_{c o}\left(1.5+12 \frac{f_{l}}{f_{c o}^{\prime}}\left(\frac{\varepsilon_{f e}}{\varepsilon_{c o}}\right)^{0.45}\right)
$$

Eq. (8) [16] for evaluating the axial strain of concrete corresponding to the maximum axial stress $\left(\varepsilon_{c c}\right)$ but to avoid excessive cracking and maintain structural integrity, the value is restricted to a maximum of 0.01 . By putting $\varepsilon \mathrm{co}=0.002, \varepsilon_{\mathrm{fu}}=0.0145$ (an average for carbon FRP computed from a database of 85 specimens), and calculating $\varepsilon f e$ from Eq. (7), and putting $\varepsilon_{\mathrm{cc}}=0.01$ in Eq. (8) the lower and upper boundary for the confinement ratio $\left(f_{l} / f_{c o}\right)$ was determined by putting Eq. (9) [10]:

$$
0.08 \leq f_{l} / f_{c o} \leq 0.16
$$

in practice, achieving passive confinement ratios (fl/fco) as large as 0.7 is quite tricky, considering the larger size of real concrete columns relative to test specimens and the cost of confinement materials and Yazici and Hadi [10] used a normalized confinement stiffness $\left(K_{N}\right)$ given by Eq. (10) to express the confined concrete strain:

$$
K_{N}=\frac{2 E_{f} t_{f}}{D f_{c o}}
$$

The confinement ratio $f_{l} / f_{\text {co }}$ can be expressed by:

$$
\frac{f_{l}}{f_{c o}}=\kappa_{\varepsilon} \varepsilon_{f u} K_{N}
$$

By substituting Eq. (7) into Eq. (5), and using $\kappa \varepsilon=0.55(\kappa \varepsilon=$ strain efficiency factor, a value of 0.55 is recommended for circular crosssections), the following expression for the strain of FRP-confined concrete [10] was obtained:

$$
\frac{\varepsilon_{c c}}{\varepsilon_{c o}}=1+0.16 K_{N}
$$

The upper and lower limits of Eqn. (9) was also expressed in terms of $K_{N}$ :

$$
10 \leq K_{N} \leq 20
$$

\subsection{Database}

A database of recent works exe(5)ted in the period 2019-2020 was compiled. The database comprises nine papers $[1,2,20,3,19,4,5,7,14]$ related to PTCI directly or indirectly. The number of test data for the strain of PTCI specimens reported in the literature is limited and less than those for strength. Therefore, the database included only nine recent studies, and the entire test data are summarized in Table 2.

\subsection{PTCI}

For PTCI: a model proposed for the strain of concrete specimens with circular cross-sections confined with a plastic tube. In the present study, the average peak strain of PTCI specimens was calculated from Table 2 and was found to be $\varepsilon_{\mathrm{fu}}=0.00827$ and substituting in Eqn. (11): (6)

$$
\frac{f_{l}}{f_{c o}}=(0.00827) K_{N}
$$

By substituting (14) into (4)

$$
\frac{f_{c c}}{f_{c o}}=1+0.034 K_{N}
$$

Eqn. (15) into (5):

$$
\frac{\varepsilon_{c c}}{\varepsilon_{c o}}=1+0.17 K_{N}
$$

With strain efficiency factor $\kappa \varepsilon=1$ (value 0.55 recommended for circular cross-sections).

Recently Abdulla [19] proposed a model for the strain of PTCI specimens based on using a soft computing technique, artificial neural work (ANN):

(8)

$$
\left(\frac{\varepsilon_{\mathrm{cu}}}{\varepsilon_{\mathrm{co}}}\right)_{\mathrm{ANN}}=1.29\left(\frac{\mathrm{f}_{\mathrm{l}}}{\mathrm{f}_{\mathrm{co}}}\right)^{-0.54}
$$

By substituting Eqn. (14) into Eqn. (17): 


$$
\left(\frac{\varepsilon_{\mathrm{cu}}}{\varepsilon_{\mathrm{co}}}\right)_{\mathrm{ANN}}=1.29\left(0.00827 K_{N}\right)^{-0.54}
$$

$K_{N P V C}$ was calculated from Eq.(10), and to account for premature failure of the plastic tube, a modifications factor was used and rendered it more effective in predicting the strength of PTCI.

$$
10 \leq K_{N P V C} \leq 20
$$

\subsection{Statistical Indexes}

Three statistical indexes were used to evaluate the proposed and the three existing FRP-confined concrete strain models' performance. The indexes included: Average absolute relative error (AAE), Normalized root-mean-square error (NRMSE), and coefficient of correlation $\left(R^{2}\right)$ :

$$
\begin{aligned}
& A A E=\frac{\sum_{i=1}^{N}\left|\frac{\text { model. } i \text { exp. } i}{\text { exp.i }}\right|}{N} \\
& \text { NRMSE }=\frac{\sqrt{\frac{\sum_{i=1}^{N}(\text { exp. } i-\text { model. } .)^{2}}{N}}}{\sum_{i=1}^{N} \text { exp. } i}
\end{aligned}
$$

Where (exp.i)= the experimental result; (model.i)=the model prediction; $\mathrm{N}=$ the total number of data. AAE's and NRMSE's small values show well model performance. Since most values of RMSE are smaller than those of $\mathrm{AAE}$, the former is easier and more practical to use.

\subsection{Predicted $\varepsilon_{\mathrm{cc}} / \varepsilon_{\text {coModel }}$ versus $\varepsilon_{\mathrm{cc}} / \varepsilon_{\mathrm{co-Exp}}$}

The Predicted $\varepsilon_{\mathrm{cc}} / \varepsilon_{\mathrm{coM} \text { odel }}$ versus $\varepsilon_{\mathrm{cc}} / \varepsilon_{\mathrm{co}-\mathrm{Exp}}$ using models 1,2 , and 3 are depicted in Figs 8 and 9. Model 2 by Wu et al. [12] shows a better fit of predicted results with the experimental results than models 1 and 3 . Model 2 shows good predictions of test results for PTCI specimens with both normal and high strength concretes. However, model 2 displays poor predictions for PTCI columns with low strength. Predicted $\varepsilon_{\mathrm{cc}} / \varepsilon_{\text {coModel }}$ versus $\varepsilon_{\mathrm{cc}} / \varepsilon_{\text {co-Exp }}$ using models 12 and 13 are drawn in Fig.10. Nearly more than half of the predicted results fall within the $20 \%$ error lines. But the models show poor predictions for low strength concrete confined with the polymeric tube. Fig. 11 (a) and (b) shows the prediction of model 16 without and with the limit $10 \leq K_{N} \leq 20$. The predicted data fits within the upper and lower $20 \%$ boundaries, but it deviates from the best fitting line as the strength of concrete decreases. The limit $10 \leq \mathrm{K}_{\mathrm{N}} \leq 20$ has little influence on the fitting of predicted values with the test values. Model 17 shows low predictions of test data where there is a spread of data, Fig.12. Similar observations can be made for models 18 without and limit $10 \leq K_{N} \leq 20$, Fig.13.

\subsection{Performance of models}

The predictions by the FRP models and the proposed model are shown in Figs. 8 to 13. Two comparisons were made; one general that included all test results, and a second one for experimental results with $\mathrm{KN}$ values between 10 and 20 according to ACI 440-2R (ACI 2008) [16] recommendations for stress strain limitations. The accuracy of the models was evaluated using statistical indexes, which were also used for comparison purposes. Ilki et al. [11], Eq. (1) could result in larger average absolute errors, 189\%, ecc/eco values, and a high RMSE value of 4.63. Wu et al. [12] model yielded reasonable predictions with $\mathrm{AAE}$ and RMSE values of $31.24 \%$ and 1.93 , respectively.

The model by Mohamed and Masmoudi [13] produced higher errors with $\mathrm{AAE}$ and RMSE values of $41.34 \%$ and 1.6, respectively. Model 12 by Yazici and Hadi [10] made lower errors with AAE and RMSE of 31\% and 1.57, respectively. The computed average absolute error for the proposed model 16 was similar to that of model 12 with an AAE of $31.7 \%$. However, the RMSE value for the proposed model 16 was only 1.52, compared with 1.57 for model 12. The RMSE value for the proposed model 16 was the lowest among all models under discussion.

The proposed models 17 and 18 produced higher errors compared with the proposed model 16.
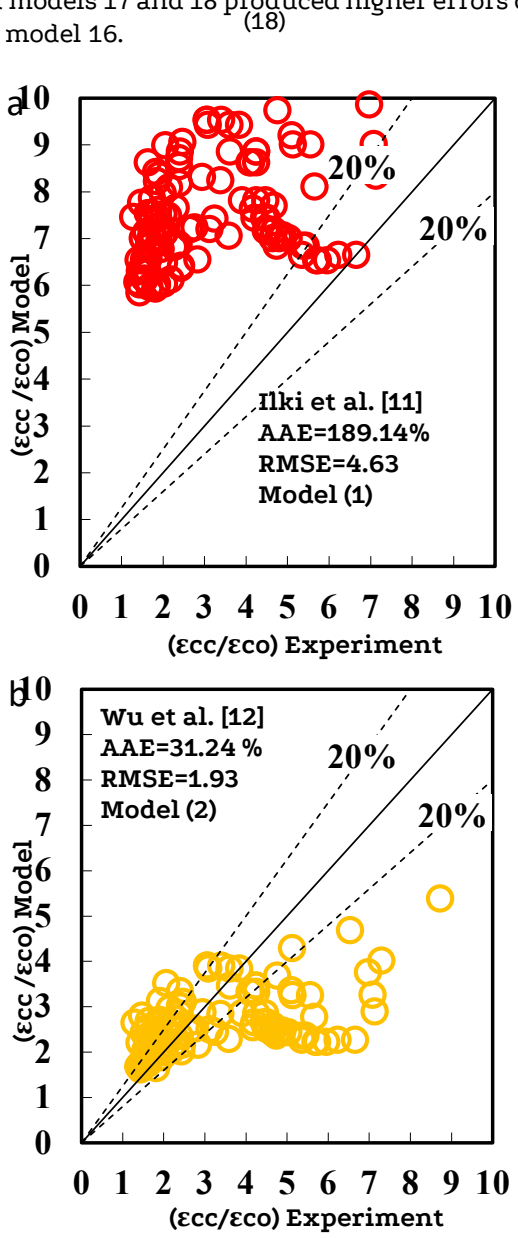

Fig. (8) Predicted $\varepsilon_{\mathrm{cc}} / \varepsilon_{\text {coModel versus }} \varepsilon_{\mathrm{cc}} / \varepsilon_{\mathrm{co}-\text {-Exp }}$ using the model: (a) 1; (b) 2.

The model providing a smaller sum of squared errors was accepted as a a better model than the other models. The average absolute error of $30 \%$ is not unfamiliar for $\varepsilon c c / \varepsilon c 0$ values, and several studies for FRP confined concrete have reported similar values [10].

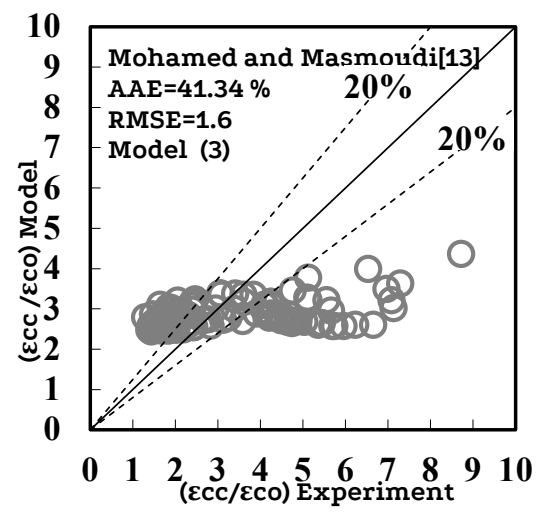

Fig. (9) Predicted $\varepsilon_{\mathrm{cc}} / \varepsilon_{\text {coModel }}$ versus $\varepsilon_{\mathrm{cc}} / \varepsilon_{\mathrm{co} \text {-Exp }}$ using model 3.

For $\mathrm{K}_{\mathrm{N}}$ results between 10 and 20 , only three models were considered: model 12,16 , and 18 . Because of the parameter $\mathrm{KN}$, the other models were not applicable. The predicted $\varepsilon c c / \varepsilon c o$ values for model 16 were closer to the experimental values over the given database. The 
proposed model 16 was more accurate than the other two models 12 and 18,
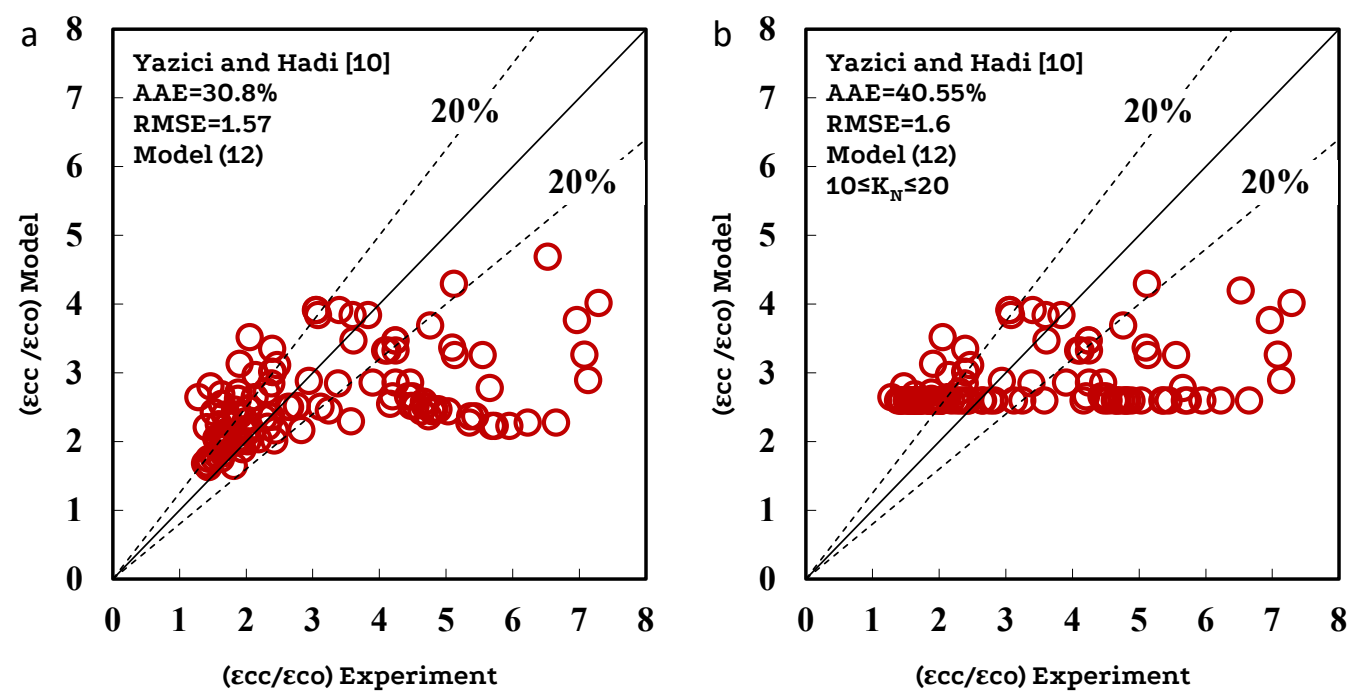

Fig. (10) Predicted $\varepsilon_{\mathrm{cc}} / \varepsilon_{\text {coModel }}$ versus $\varepsilon_{\mathrm{cc}} / \varepsilon_{\mathrm{co}-\mathrm{Exp}}$ using the model: (a) 12 ; (b) 12 with the limit $10 \leq \mathrm{K}_{\mathrm{N}} \leq 20$.
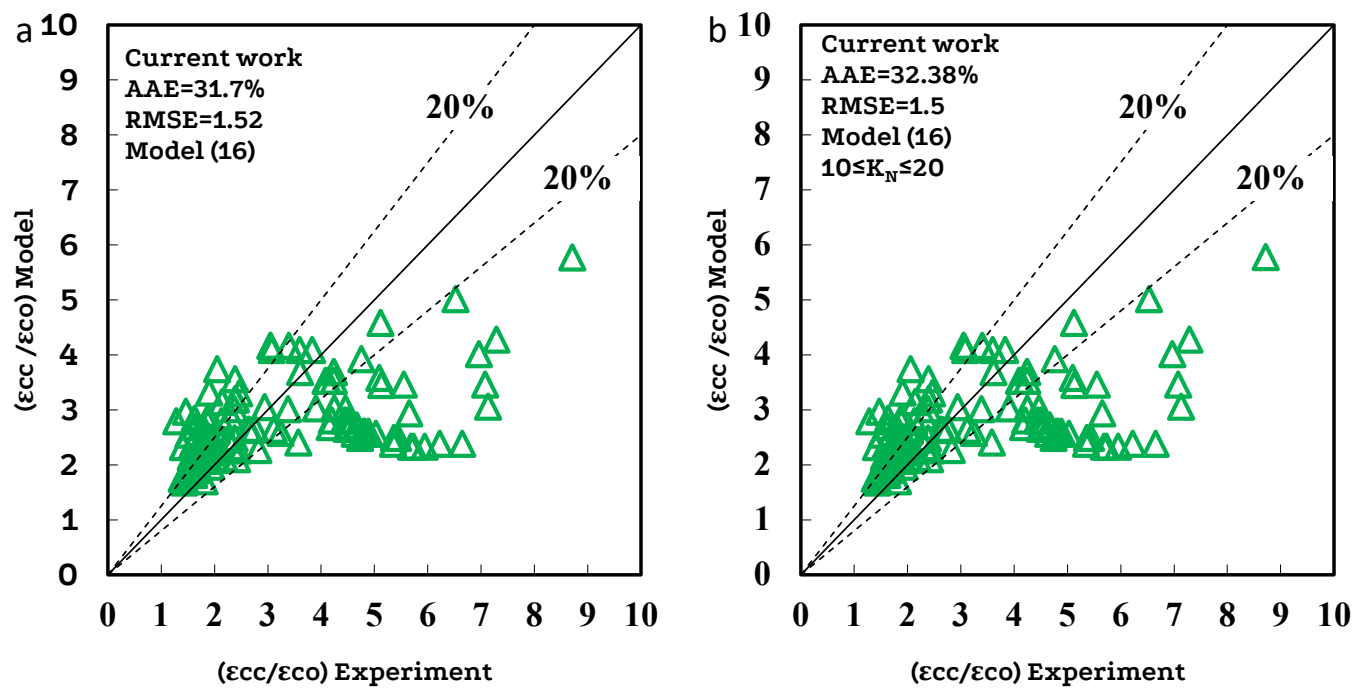

Fig. (11) Predicted $\varepsilon_{\mathrm{cc}} / \varepsilon_{\text {coModel versus }} \varepsilon_{\mathrm{cc}} / \varepsilon_{\mathrm{co}-\text { Exp }}$ using the model: (a) 16 ; (b) 16 with the limit $10 \leq \mathrm{K}_{\mathrm{N}} \leq 20$.

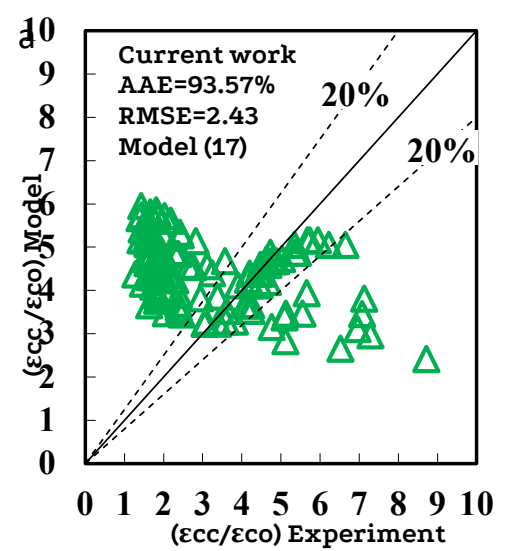

Fig. (12) Predicted $\varepsilon_{\mathrm{cc}} / \varepsilon_{\text {coModel }}$ versus $\varepsilon_{\mathrm{cc}} / \varepsilon_{\mathrm{co}-\text { Exp }}$ using model 17. 
Table 2 Assembled database for CFPT from recent studies, 2019-2020.

\begin{tabular}{|c|c|c|c|c|c|c|c|c|c|c|c|c|c|}
\hline Sourceofdata & Specimens & $\begin{array}{l}\mathrm{tP} \\
\mathrm{mm}\end{array}$ & $\begin{array}{l}\text { Dex } \\
\text { mm }\end{array}$ & $\begin{array}{l}\text { Ap } \\
\mathrm{mm}^{2}\end{array}$ & $\begin{array}{l}\mathrm{Ac} \\
\mathrm{mm}^{2}\end{array}$ & $\begin{array}{l}\mathrm{H} \\
\mathrm{mm}\end{array}$ & $\mathrm{H} / \mathrm{D}$ & $\begin{array}{l}\text { fyp } \\
\mathrm{MPa}\end{array}$ & $\begin{array}{l}\text { fcc/ } \\
\text { fcoex }\end{array}$ & $\begin{array}{l}\mathrm{E} \\
\mathrm{MPa}\end{array}$ & $\mathrm{K}_{\mathrm{N}}$ & $\begin{array}{l}10 \leq \mathrm{K}_{\mathrm{N}} \\
\leq 20\end{array}$ & $\begin{array}{l}\text { fl/ } \\
\text { fco }\end{array}$ \\
\hline \multirow[t]{3}{*}{ Abdulla(2019)[1] } & 1-SF & 4 & 75 & 892.57 & 4419. & 150 & 2 & 48 & 1.22 & 3900 & 13.21 & 13.21 & 0.11 \\
\hline & $2-S F$ & 4.5 & 90 & 1209. & 6364. & 180 & 2 & 48 & 1.17 & 3900 & 12.56 & 12.56 & 0.1 \\
\hline & $3-S F$ & 5 & 110 & 1650 & 9507. & 220 & 2 & 48 & 1.19 & 3900 & 11.57 & 11.57 & 0.1 \\
\hline \multirow{20}{*}{$\begin{array}{l}\text { Woldemariam } \\
\text { etal.(2019)[2] }\end{array}$} & C1P1H1 & 2.5 & 68 & 514.64 & 3633.1 & 136 & 2 & 41 & 2.36 & 3580 & 27.45 & 20 & 0.23 \\
\hline & $\mathrm{C} 1 \mathrm{P} 2 \mathrm{H} 1$ & 3 & 96 & 876.86 & 7241. & 192 & 2 & 41 & 2.23 & 3580 & 23.06 & 20 & 0.19 \\
\hline & C1P3H1 & 3 & 116 & 1065. & 10573 & 232 & 2 & 41 & 2.13 & 3580 & 18.87 & 18.87 & 0.16 \\
\hline & C1P4H1 & 3 & 146 & 1348.3 & 16748 & 292 & 2 & 41 & 2.03 & 3580 & 14.82 & 14.82 & 0.12 \\
\hline & $\mathrm{C} 2 \mathrm{P} 1 \mathrm{H} 1$ & 2.5 & 68 & 514.64 & 3633.1 & 136 & 2 & 41 & 1.99 & 3580 & 20.6 & 20 & 0.17 \\
\hline & $\mathrm{C} 2 \mathrm{P} 2 \mathrm{H} 1$ & 3 & 96 & 876.86 & 7241. & 192 & 2 & 41 & 1.94 & 3580 & 17.31 & 17.31 & 0.14 \\
\hline & С2P3H1 & 3 & 116 & 1065. & 10573 & 232 & 2 & 41 & 1.81 & 3580 & 14.16 & 14.16 & 0.12 \\
\hline & $\mathrm{C} 2 \mathrm{P} 4 \mathrm{H} 1$ & 3 & 146 & 1348.3 & 16748 & 292 & 2 & 41 & 1.72 & 3580 & 11.13 & 11.13 & 0.0 \\
\hline & С3Р1H1 & 2.5 & 68 & 514.64 & 3633.1 & 136 & 2 & 41 & 1.7 & 3580 & 16.82 & 16.82 & 0.14 \\
\hline & С3Р2H1 & 3 & 96 & 876.86 & 7241. & 192 & 2 & 41 & 1.69 & 3580 & 14.13 & 14.13 & 0.12 \\
\hline & С3Р3Н1 & 3 & 116 & 1065.4 & 10573 & 232 & 2 & 41 & 1.6 & 3580 & 11.56 & 11.56 & 0.1 \\
\hline & С3Р4H1 & 3 & 146 & 1348.3 & 16748 & 292 & 2 & 41 & 1.45 & 3580 & 9.08 & 10 & 0.0 \\
\hline & C4P1H1 & 2.5 & 68 & 514.64 & 3633.1 & 136 & 2 & 41 & 1.6 & 3580 & 14.11 & 14.11 & 0.12 \\
\hline & C4P2H1 & 3 & 96 & 876.86 & 7241. & 192 & 2 & 41 & 1.52 & 3580 & 11.86 & 11.86 & 0.1 \\
\hline & C4P3H1 & 3 & 116 & 1065.4 & 10573 & 232 & 2 & 41 & 1.47 & 3580 & 9.701 & 10 & 0.0 \\
\hline & $\mathrm{C} 4 \mathrm{P} 4 \mathrm{H} 1$ & 3 & 146 & 1348.3 & 16748 & 292 & 2 & 41 & 1.39 & 3580 & 7.622 & 10 & 0.0 \\
\hline & C5P1H1 & 2.5 & 68 & 514.64 & 3633.1 & 136 & 2 & 41 & 1.44 & 3580 & 11.78 & 11.78 & 0.1 \\
\hline & C5P2H1 & 3 & 96 & 876.86 & 7241. & 192 & 2 & 41 & 1.42 & 3580 & 9.895 & 10 & 0.0 \\
\hline & С5Р3H1 & 3 & 116 & 1065.4 & 10573 & 232 & 2 & 41 & 1.36 & 3580 & 8.09 & 10 & 0.0 \\
\hline & C5P4H1 & 3 & 146 & 1348.3 & 16748 & 292 & 2 & 41 & 1.28 & 3580 & 6.361 & 10 & 0.0 \\
\hline Lu2019[20] & PVC-RACO & 3.2 & 110 & 1074.1 & 9507. & 300 & 2.7 & 37 & 1.43 & 3500 & 7.305 & 10 & 0.0 \\
\hline \multirow[t]{12}{*}{ Abdulla(2020)[3] } & $\mathrm{CT}-\mathrm{A} 1$ & 3.8 & 110 & 1268.3 & 9507. & 200 & 1.8 & 40 & 1.22 & 400 & 7.671 & 10 & 0.0 \\
\hline & CT-A2 & 3.8 & 110 & 1268.3 & 9507. & 200 & 1.8 & 40 & 1.25 & 400 & 7.671 & 10 & 0.0 \\
\hline & CT-A3 & 3.8 & 110 & 1268.3 & 9507. & 200 & 1.8 & 40 & 1.23 & 400 & 7.671 & 10 & 0.0 \\
\hline & CT-B1 & 3.8 & 110 & 1268.3 & 9507. & 200 & 1.8 & 40 & 1.24 & 400 & 7.981 & 10 & 0.0 \\
\hline & CT-B2 & 3.8 & 110 & 1268.3 & 9507. & 200 & 1.8 & 40 & 1.25 & 400 & 7.981 & 10 & 0.0 \\
\hline & СТ-B3 & 3.8 & 110 & 1268.3 & 9507. & 200 & 1.8 & 40 & 1.28 & 400 & 7.981 & 10 & 0.0 \\
\hline & CT-C1 & 3.8 & 110 & 1268.3 & 9507. & 200 & 1.8 & 40 & 1.29 & 400 & 8.555 & 10 & 0.0 \\
\hline & СТ-C2 & 3.8 & 110 & 1268.3 & 9507. & 200 & 1.8 & 40 & 1.28 & 400 & 8.555 & 10 & 0.0 \\
\hline & CT-C3 & 3.8 & 110 & 1268.3 & 9507. & 200 & 1.8 & 40 & 1.32 & 400 & 8.555 & 10 & 0.0 \\
\hline & CT-D1 & 3.8 & 110 & 1268.3 & 9507. & 200 & 1.8 & 40 & 1.26 & 400 & 9.02 & 10 & 0.0 \\
\hline & CT-D2 & 3.8 & 110 & 1268.3 & 9507. & 200 & 1.8 & 40 & 1.39 & 400 & 9.02 & 10 & 0.0 \\
\hline & CT-D3 & 3.8 & 110 & 1268.3 & 9507. & 200 & 1.8 & 40 & 1.35 & 400 & 9.02 & 10 & 0.0 \\
\hline \multirow[t]{24}{*}{ Abdulla(2020)JSC[19] } & CT-E1 & 3.8 & 110 & 1268.3 & 9507. & 200 & 1.8 & 40 & 1.37 & 400 & 9.22 & 10 & 0.0 \\
\hline & CT-E2 & 3.8 & 110 & 1268.3 & 9507. & 200 & 1.8 & 40 & 1.4 & 400 & 9.22 & 10 & 0.0 \\
\hline & CT-E3 & 3.8 & 110 & 1268.3 & 9507. & 200 & 1.8 & 40 & 1.39 & 400 & 9.22 & 10 & 0.0 \\
\hline & CT-F1 & 3.8 & 110 & 1268.3 & 9507. & 200 & 1.8 & 40 & 1.36 & 400 & 9.515 & 10 & 0.0 \\
\hline & $\mathrm{CT}-\mathrm{F} 2$ & 3.8 & 110 & 1268.3 & 9507. & 200 & 1.8 & 40 & 1.41 & 400 & 9.515 & 10 & 0.0 \\
\hline & CT-F3 & 3.8 & 110 & 1268.3 & 9507. & 200 & 1.8 & 40 & 1.43 & 400 & 9.515 & 10 & 0.0 \\
\hline & CT-G1 & 3.8 & 110 & 1268.3 & 9507. & 200 & 1.8 & 40 & 1.4 & 400 & 10.38 & 10.38 & 0.0 \\
\hline & CT-G2 & 3.8 & 110 & 1268.3 & 9507. & 200 & 1.8 & 40 & 1.43 & 400 & 10.38 & 10.38 & 0.0 \\
\hline & CT-G3 & 3.8 & 110 & 1268.3 & 9507. & 200 & 1.8 & 40 & 1.41 & 400 & 10.38 & 10.38 & 0.0 \\
\hline & CT-H4 & 3.8 & 110 & 1268.3 & 9507. & 200 & 1.8 & 40 & 1.48 & 400 & 11.64 & 11.64 & 0.1 \\
\hline & CT-H5 & 3.8 & 110 & 1268.3 & 9507. & 200 & 1.8 & 40 & 1.51 & 400 & 11.64 & 11.64 & 0.1 \\
\hline & CT-H6 & 3.8 & 110 & 1268.3 & 9507. & 200 & 1.8 & 40 & 1.45 & 400 & 11.64 & 11.64 & 0.1 \\
\hline & CT-I1 & 3.8 & 110 & 1268.3 & 9507. & 200 & 1.8 & 40 & 1.54 & 400 & 14.55 & 14.55 & 0.12 \\
\hline & CT-I2 & 3.8 & 110 & 1268.3 & 9507. & 200 & 1.8 & 40 & 1.59 & 400 & 14.55 & 14.55 & 0.12 \\
\hline & CT-I3 & 3.8 & 110 & 1268.3 & 9507. & 200 & 1.8 & 40 & 1.57 & 400 & 14.55 & 14.55 & 0.12 \\
\hline & CT-J4 & 3.8 & 110 & 1268.3 & 9507. & 200 & 1.8 & 40 & 1.64 & 400 & 15.46 & 15.46 & 0.13 \\
\hline & CT-J5 & 3.8 & 110 & 1268.3 & 9507. & 200 & 1.8 & 40 & 1.64 & 400 & 15.46 & 15.46 & 0.13 \\
\hline & CT-J6 & 3.8 & 110 & 1268.3 & 9507. & 200 & 1.8 & 40 & 1.69 & 400 & 15.46 & 15.46 & 0.13 \\
\hline & CT-K1 & 3.8 & 110 & 1268.3 & 9507. & 200 & 1.8 & 40 & 1.76 & 400 & 17.78 & 17.78 & 0.15 \\
\hline & CT-K2 & 3.8 & 110 & 1268.3 & 9507. & 200 & 1.8 & 40 & 1.79 & 400 & 17.78 & 17.78 & 0.15 \\
\hline & CT-K3 & 3.8 & 110 & 1268.3 & 9507. & 200 & 1.8 & 40 & 1.75 & 400 & 17.78 & 17.78 & 0.15 \\
\hline & CT-L4 & 3.8 & 110 & 1268.3 & 9507. & 200 & 1.8 & 40 & 1.86 & 400 & 18.21 & 18.21 & 0.15 \\
\hline & CT-L5 & 3.8 & 110 & 1268.3 & 9507. & 200 & 1.8 & 40 & 1.84 & 400 & 18.21 & 18.21 & 0.15 \\
\hline & CT-L6 & 3.8 & 110 & 1268.3 & 9507. & 200 & 1.8 & 40 & 1.82 & 400 & 18.21 & 18.21 & 0.15 \\
\hline \multirow[t]{2}{*}{ Abdulla(2020)KSCE[5] } & 1 & 4 & 90 & 1081.1 & 6364. & 180 & 2 & 40 & 1.22 & 3950 & 12.31 & 12.31 & 0.1 \\
\hline & 2 & 5 & 110 & 1650 & 9507. & 220 & 2 & 40 & 1.18 & 3950 & 12.62 & 12.62 & 0.1 \\
\hline \multirow[t]{3}{*}{ Abdulla(2020)[4]jordan } & $1-10 s$ & 4 & 75 & 892.57 & 4419. & 150 & 2 & 41 & 1.22 & 400 & 15.76 & 15.76 & 0.13 \\
\hline & $1-11 s$ & 4.5 & 90 & 1209. & 6364. & 180 & 2 & 41 & 1.13 & 400 & 14.72 & 14.72 & 0.12 \\
\hline & $1-13 s$ & 5 & 110 & 1650 & 9507. & 220 & 2 & 41 & 1.28 & 400 & 13.33 & 13.33 & 0.11 \\
\hline
\end{tabular}


Table 2 Assembled database for CFPT from recent studies, 2019-2020.(Continued)

\begin{tabular}{|c|c|c|c|c|c|c|c|c|c|c|c|c|c|}
\hline Sourceofdata & Specimens & $\begin{array}{l}\mathrm{tP} \\
\mathrm{mm}\end{array}$ & $\begin{array}{l}\text { Dex } \\
\text { mm }\end{array}$ & $\begin{array}{l}\mathrm{Ap} \\
\mathrm{mm}^{2}\end{array}$ & $\begin{array}{l}\mathrm{Ac} \\
\mathrm{mm}^{2}\end{array}$ & $\begin{array}{l}\mathrm{H} \\
\mathrm{mm}\end{array}$ & $\mathrm{H} / \mathrm{D}$ & $\begin{array}{l}\text { fyp } \\
\mathrm{MPa}\end{array}$ & $\begin{array}{l}\mathrm{fcc} / \\
\text { fcoex }\end{array}$ & $\begin{array}{l}\mathrm{E} \\
\mathrm{MPa}\end{array}$ & $\mathrm{K}_{\mathrm{N}}$ & $\begin{array}{l}10 \leq K_{N} \\
\leq 20\end{array}$ & $\begin{array}{l}\text { fl/ } \\
\text { fco }\end{array}$ \\
\hline \multirow[t]{24}{*}{ Askerietal.[7] } & C40-6-0\#1 & 3 & 110 & 1008. & 9507. & 220 & 2 & 48 & 1.15 & 320 & 5.715 & 10 & 0.05 \\
\hline & C40-6-0\#2 & 3 & 110 & 1008. & 9507. & 220 & 2 & 48 & 1.18 & 320 & 5.672 & 10 & 0.05 \\
\hline & C40-6-1\#1 & 3.1 & 110 & 1041.5 & 9507. & 220 & 2 & 48 & 1 & 320 & 4.684 & 10 & 0.0 \\
\hline & C40-6-1\#2 & 3.1 & 110 & 1041.5 & 9507. & 220 & 2 & 48 & 1.15 & 320 & 5.142 & 10 & 0.0 \\
\hline & C40-6-3\#1 & 3.1 & 110 & 1041.5 & 9507. & 220 & 2 & 48 & 1.04 & 320 & 5.176 & 10 & 0.0 \\
\hline & C40-6-3\#2 & 3.1 & 110 & 1041.5 & 9507. & 220 & 2 & 48 & 1.19 & 320 & 5.562 & 10 & 0.05 \\
\hline & C40-10-0\#1 & 4.9 & 110 & 1618.5 & 9507. & 220 & 2 & 48 & 1.1 & 320 & 9.689 & 10 & 0.0 \\
\hline & C40-10-0\#2 & 4.7 & 110 & 1555.4 & 9507. & 220 & 2 & 48 & 1.22 & 320 & 9.186 & 10 & 0.0 \\
\hline & C40-10-1\#1 & 4.6 & 110 & 1523.8 & 9507. & 220 & 2 & 48 & 0.95 & 320 & 7.157 & 10 & 0.0 \\
\hline & C40-10-1\#2 & 4.6 & 110 & 1523.8 & 9507. & 220 & 2 & 48 & 1.11 & 320 & 7.856 & 10 & 0.0 \\
\hline & C40-10-3\#1 & 4.7 & 110 & 1555.4 & 9507. & 220 & 2 & 48 & 1 & 320 & 8.097 & 10 & 0.07 \\
\hline & C40-10-3\#2 & 4.7 & 110 & 1555.4 & 9507. & 220 & 2 & 48 & 1.14 & 320 & 8.7 & 10 & 0.07 \\
\hline & C50-6-0\#1 & 3.3 & 110 & 1106.6 & 9507. & 220 & 2 & 48 & 1.09 & 320 & 4.69 & 10 & 0.0 \\
\hline & C50-6-0\#2 & 3.1 & 110 & 1041.5 & 9507. & 220 & 2 & 48 & 1.2 & 320 & 4.761 & 10 & 0.0 \\
\hline & C50-6-1\#1 & 3.1 & 110 & 1041.5 & 9507. & 220 & 2 & 48 & 1.06 & 320 & 3.926 & 10 & 0.03 \\
\hline & C50-6-1\#2 & 3.1 & 110 & 1041.5 & 9507 & 220 & 2 & 48 & 1.2 & 320 & 4.289 & 10 & 0.0 \\
\hline & C50-6-3\#1 & 3.1 & 110 & 1041.5 & 9507. & 220 & 2 & 48 & 1.08 & 320 & 4.198 & 10 & 0.03 \\
\hline & C50-6-3\#2 & 3 & 110 & 1008. & 9507. & 220 & 2 & 48 & 1.13 & 320 & 4.05 & 10 & 0.03 \\
\hline & C50-10-0\#1 & 4.5 & 110 & 1492.1 & 9507. & 220 & 2 & 48 & 1.05 & 320 & 6.55 & 10 & 0.05 \\
\hline & C50-10-0\#2 & 4.5 & 110 & 1492.1 & 9507. & 220 & 2 & 48 & 1.17 & 320 & 7.102 & 10 & 0.0 \\
\hline & C50-10-1\#1 & 4.8 & 110 & 1587 & 9507. & 220 & 2 & 48 & 1.01 & 320 & 6.284 & 10 & 0.05 \\
\hline & C50-10-1\#2 & 4.8 & 110 & 1587 & 9507. & 220 & 2 & 48 & 1.02 & 320 & 6.867 & 10 & 0.0 \\
\hline & C50-10-3\#1 & 4.5 & 110 & 1492.1 & 9507. & 220 & 2 & 48 & 1.03 & 320 & 6.262 & 10 & 0.05 \\
\hline & C50-10-3\#2 & 4.5 & 110 & 1492.1 & 9507. & 220 & 2 & 48 & 1.02 & 320 & 6.262 & 10 & 0.05 \\
\hline \multirow[t]{18}{*}{ Abdulla(2020)structures[21] } & A-0-1 & 3.9 & 110 & 1300.5 & 9507. & 220 & 2 & 41 & 1.34 & 400 & 11.31 & 11.31 & 0.0 \\
\hline & $A-0-2$ & 3.9 & 110 & 1300.5 & 9507. & 220 & 2 & 41 & 1.3 & 400 & 10.56 & 10.56 & 0.0 \\
\hline & A-0-3 & 3.9 & 110 & 1300.5 & 9507. & 220 & 2 & 41 & 1.29 & 400 & 10.31 & 10.31 & 0.0 \\
\hline & $A-1-1$ & 3.9 & 110 & 1300.5 & 9507. & 220 & 2 & 41 & 1.21 & 400 & 8.722 & 10 & 0.07 \\
\hline & A-1-2 & 3.9 & 110 & 1300.5 & 9507. & 220 & 2 & 41 & 1.22 & 400 & 8.926 & 10 & 0.07 \\
\hline & A-1-3 & 3.9 & 110 & 1300.5 & 9507. & 220 & 2 & 41 & 1.19 & 400 & 8.527 & 10 & 0.07 \\
\hline & B-1-1 & 3.9 & 110 & 1300.5 & 9507. & 220 & 2 & 41 & 1.16 & 400 & 7.828 & 10 & 0.0 \\
\hline & B-1-2 & 3.9 & 110 & 1300.5 & 9507. & 220 & 2 & 41 & 1.15 & 400 & 7.594 & 10 & 0.0 \\
\hline & B-1-3 & 3.9 & 110 & 1300.5 & 9507. & 220 & 2 & 41 & 1.14 & 400 & 7.428 & 10 & 0.0 \\
\hline & $C-1-1$ & 3.9 & 110 & 1300.5 & 9507. & 220 & 2 & 41 & 1.13 & 400 & 7.269 & 10 & 0.0 \\
\hline & $C-1-2$ & 3.9 & 110 & 1300.5 & 9507. & 220 & 2 & 41 & 1.11 & 400 & 6.891 & 10 & 0.0 \\
\hline & $C-1-3$ & 3.9 & 110 & 1300.5 & 9507. & 220 & 2 & 41 & 1.09 & 400 & 6.551 & 10 & 0.05 \\
\hline & D-1-1 & 3.9 & 110 & 1300.5 & 9507. & 220 & 2 & 41 & 1.08 & 400 & 6.282 & 10 & 0.05 \\
\hline & D-1-2 & 3.9 & 110 & 1300.5 & 9507. & 220 & 2 & 41 & 1.09 & 400 & 6.495 & 10 & 0.05 \\
\hline & D-1-3 & 3.9 & 110 & 1300.5 & 9507. & 220 & 2 & 41 & 1.09 & 400 & 6.50 & 10 & 0.05 \\
\hline & E-1-1 & 3.9 & 110 & 1300.5 & 9507. & 220 & 2 & 41 & 1.07 & 400 & 6.18 & 10 & 0.05 \\
\hline & E-1-2 & 3.9 & 110 & 1300.5 & 9507. & 220 & 2 & 41 & 1.07 & 400 & 6.09 & 10 & 0.05 \\
\hline & E-1-3 & 3.9 & 110 & 1300.5 & 9507. & 220 & 2 & 41 & 1.08 & 400 & 6.269 & 10 & 0.05 \\
\hline \multirow[t]{12}{*}{ Presentstudy } & S1-H1-1 & 4.1 & 110 & 1364.6 & 9507. & 110 & 1 & 40 & 1.32 & 3950 & 7.837 & 10 & 0.0 \\
\hline & S1-H1-2 & 4.0 & 110 & 1339 & 9507. & 110 & 1 & 40 & 1.33 & 3950 & 7.787 & 10 & 0.0 \\
\hline & S2-H1-1 & 6.0 & 110 & 1976.5 & 9507. & 110 & 1 & 40 & 1.15 & 3950 & 9.353 & 10 & 0.0 \\
\hline & S2-H1-2 & 6.1 & 110 & 1998.1 & 9507. & 110 & 1 & 40 & 1.13 & 3950 & 9.261 & 10 & 0.0 \\
\hline & S3-H2-1 & 4.2 & 110 & 1396.6 & 9507. & 165 & 1.5 & 40 & 1.29 & 3950 & 8.417 & 10 & 0.07 \\
\hline & S3-H2-2 & 4 & 110 & 1332.6 & 9507. & 165 & 1.5 & 40 & 1.32 & 3950 & 8.328 & 10 & 0.07 \\
\hline & $\mathrm{S} 4-\mathrm{H} 2-1$ & 6.1 & 110 & 1995 & 9507. & 165 & 1.5 & 40 & 1.11 & 3950 & 9.493 & 10 & 0.0 \\
\hline & $\mathrm{S} 4-\mathrm{H} 2-2$ & 6.0 & 110 & 1982.7 & 9507. & 165 & 1.5 & 40 & 1.1 & 3950 & 9.237 & 10 & 0.0 \\
\hline & S5-H3-1 & 4.0 & 110 & 1345.4 & 9507. & 220 & 2 & 40 & 1.29 & 3950 & 9.665 & 10 & 0.0 \\
\hline & S5-H3-2 & 4.0 & 110 & 1335.8 & 9507. & 220 & 2 & 40 & 1.24 & 3950 & 9.799 & 10 & 0.0 \\
\hline & S6-H3-1 & 6.1 & 110 & 2010. & 9507. & 220 & 2 & 40 & 1.05 & 3950 & 9.749 & 10 & 0.0 \\
\hline & S6-H3-2 & 6.1 & 110 & 1991.9 & 9507. & 220 & 2 & 40 & 1.04 & 3950 & 9.777 & 10 & 0.0 \\
\hline
\end{tabular}



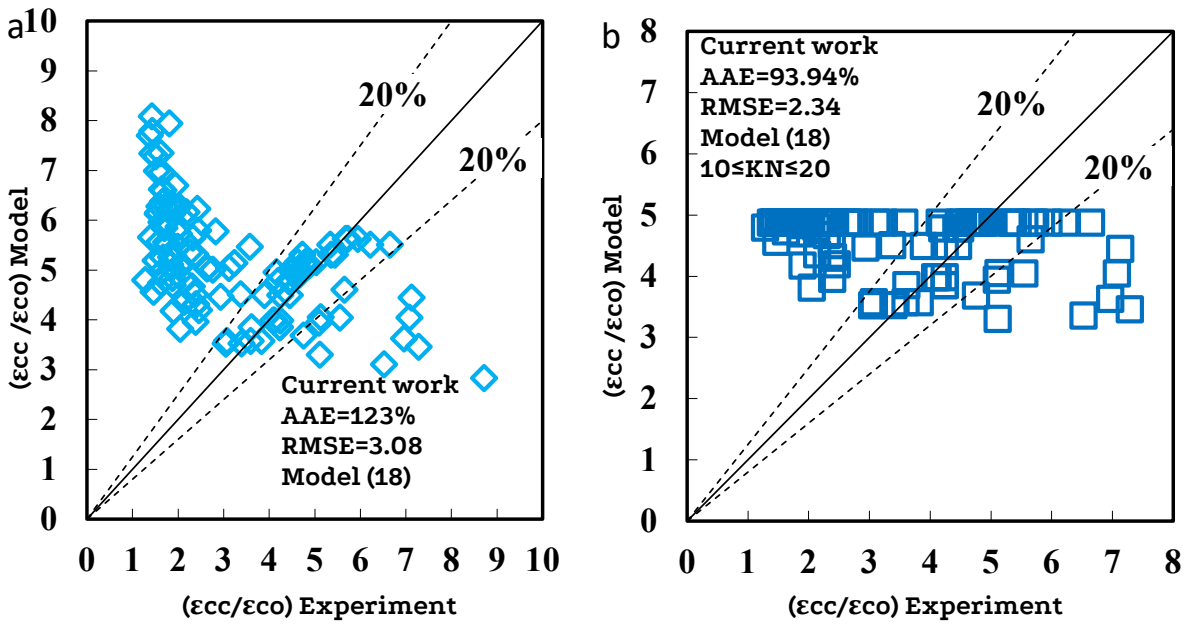

Fig. (13) Predicted $\varepsilon_{\mathrm{cc}} / \varepsilon_{\text {comodel }}$ versus $\varepsilon_{\mathrm{cc}} / \varepsilon_{\mathrm{co}-\mathrm{Exp}}$ using the model: (a) 18 ; (b) 18 with the limit $10 \leq \mathrm{K}_{\mathrm{N}} \leq 20$.

respectively. For the overall database of $\varepsilon c c / \varepsilon c o$ values, for $\mathrm{K}_{\mathrm{N}}$ values between 10 and 20, the proposed model 16 with AAE and RMSE values of $32.38 \%$ and 1.5 , was better than the predictions by model 12 for the strain of FRP-confined concrete [10] with AAE and RMSE values of $40.55 \%$ and 1.6 , respectively. The proposed model 16 can estimate maximum axial strain values with accuracy similar to the accuracy produced by model 12 or better for $K_{N}$ values between 10 and 20 . The proposed model yielded the best predictions on the overall database, with an average absolute error of $32 \%$ compared with $35.67 \%$ for model $12[10]$.

\section{CONCLUSIONS}

A normalized confinement stiffness procedure used to develop models to evaluate the axial strain of PTCI specimens tested in the present work and those tested in very recent studies. The following conclusions can be drawn:

1- The available few strain models for PTCI specimens are based on a limited number of experimental data.

2- Using a normalized confinement stiffness procedure, three models proposed to determine the axial strain of PTCI specimens tested in the present work and those tested in very recent studies based on a comprehensive database of experimental test results.

3- The computed average absolute error of $31.7 \%$ for the proposed model 16 was similar to that of model 12 for predicting FRP-confined concrete's strain, with AAE of $30.8 \%$.

4- For the overall database of $\varepsilon c c / \varepsilon c 0$ values, for $\mathrm{K}_{N}$ values between 10 and 20, the proposed model 16 with AAE and RMSE values of $32.38 \%$ and 1.5 was better than model $12 \mathrm{AAE}$ and RMSE values of $40.55 \%$ and 1.6 , respectively.

5- For the overall database, the proposed model yielded the best predictions with an average absolute error of $32 \%$ compared with $35.67 \%$ for model 12 , for the strain of FRP-confined concrete.

Engineering plastic is a new class of construction materials that can be used in infrastructure applications such as piers and bridge columns. Its several advantages include reducing the brittleness of concrete and providing additional shear and compressive capacity. With proper design methodologies, PTCI specimens can be used for structural applications with economic and technical advantages. There is no available design guideline for uPVC tube confined concrete columns. More research is needed to narrow the gap between recent research and the use of PTCI in practice.

\section{Acknowledgments}

This research did not receive any specific grant from funding agencies in the public, commercial, or non-for-profit sectors.

\section{Declaration of Conflict of Interests}

The author declares that there is no conflict of interest. They have no known competing financial interests or personal relationships that could have appeared to influence the work reported in this paper.

\section{References}

[1.] Abdulla N A. Influence of plastic pour-in form on mechanical behavior of concrete. Structures 2019, 19: 193-202.

[2.] Woldemariam A M, Oyawa W O, Nyomboi T. Structural performance of UPVC confined concrete equivalent cylinders under axial compression loads. Buildings 2019, 9(82): DOI: 10.3390/buildings9040082

[3.] Abdulla N A. Concrete encased with engineering plastics. Journal of Civil Engineering and Construction 2020, 9 (1):31-41

[4.] Abdulla N A, The Behavior of concrete-filled Plastic Tube Specimens under Axial Load, Jordan Journal of Civil Engineering 14 (1), 69-81

[5.] Abdulla N A. Mechanical behavior of slender composite columns under axial compression load. KSCE Journal of Civil Engineering, 2020, 24(1), 208-218

[6.] Bandyopadhyay A, Samanta A K, Michel Paul K J. Assessment of axial capacity of RC stub column confined with unplasticized polyvinyl chloride pipe. Journal of the Institution of Engineers (India): Series A, 2019, 100(4), 535-546

[7.] Abdulla N A, Concrete with an outer plastic protective shell, Volume 2, Issue 6, June 2020, https://doi.org/10.1007/s42452020-2901-2

[8.] Raheemah M A, Resan S F. Experimental investigation of concrete columns enhanced by PVC Tubes. IOP Conf. Ser.: Mater. Sci. Eng., 2019, 584012047

[9.] Woldemariam A M, Oyawa W O, Nyomboi T. Behavior of concretefilled single and double-skin UPVC tubular columns under axial compression loads. The Open Construction and Building Technology Journal, 2019, 13, 164-177 
[10.] Yazici and Muhammad N. S. Hadi, Normalized Confinement Stiffness Approach for Modeling FRP-Confined Concrete, J. Compos. Constr. 2012.16:520-528.

[11.] Ilki A, Kumbasar N, Koc V. Low strength concrete members externally confined with FRP sheets. Struct Eng Mech 2004;18(2):167-94.

[12.] Wu G, Lu ZT, Wu ZS. Strength and ductility of concrete cylinders confined with FRP composites. Constr Build Mater 2006;20(3):134-48.

[13.] Mohamed H, Masmoudi R. Axial load capacity of concrete-filled FRP tube columns: experimental versus predictions. ASCE J Compos Constr 2010;14(2):231-43.

[14.] Richart, F. E., Brandtzaeg, A., and Brown, R. L. (1928). "A study of the failure of concrete under combined compressive stresses." Bulletin 185, Univ. of Illinois Engineering Experimental Station, Urbana-Champaign, IL.

[15.] De Lorenzis, L., and Tepfers, R. (2001). "A comparative study of models on confinement of concrete cylinders with FRP composites." Rep. No. 01:04, Dept. of Building Materials, Chalmers Univ. of Technology, Gothenburg, Sweden. De Lorenzis and Tepfers

[16.] American Concrete Institute (ACI). ( 2008). "Guide for the design and construction of externally bonded FRP systems for strengthening concrete structures." 440.2R-08, Farmington Hills, MI.
[17.] Lam, L., and Teng, J. G. (2003a). "Design-oriented stress-strain model for FRP-confined concrete." Constr. Build. Mater., 17(6-7), 471-489.

[18.] Lam, L., and Teng, J. G. (2003b). "Design-oriented stress-strain model for FRP-confined concrete in rectangular columns." J. Reinf. Plast. Compos., 22(13), 1149-1186.

[19.] Abdulla N A, Using the Artificial Neural Network to Predict the Axial Strength and Strain of Concrete-filled Plastic Tube, Journal of Soft Computing in Civil Engineering, 2020 - jsoftcivil.com

[20.] Jiequn Lu, Yuan Tian, Jia Geng Chen, ChenYu Zhu, FuYuan Zeng, JinCheng Yang, Wei Wang, Experimental Study on CFRP-PVC Confined RAC under Axial Compression, Solid State Phenomena, ISSN: 1662-9779, Vol. 294, pp 143-149

[21.] Abdulla N A, Axial strength of short concrete-filled plastic tube, Structures 2020

\section{How to Cite This Article}

Abdulla N A, Deformations of a plastic tube with concrete-infill under direct load, Civil Engineering Beyond Limits, 2(2021), 9-18. https://doi.org/10.36937/cebel.2021.002.002 